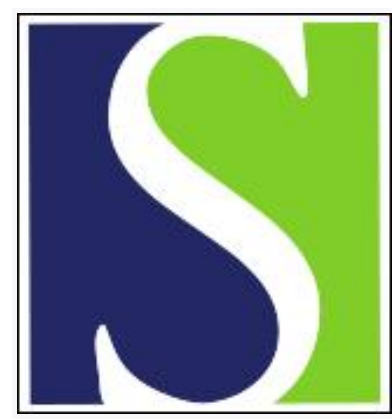

Scand J Work Environ Health 2019;45(4):421-422

https://doi.org/10.5271/sjweh.3824

Published online: 12 Apr 2019, Issue date: 01 Jul 2019

Determining an optimal minimum number of subjects in each occupation for a job exposure matrix (JEM) using self-reported data: a missing test

by Choi BK

Affiliation: Department of Medicine and Program in Public Health, University of California Irvine, 100 Theory, Suite 100, Irvine, CA 92617, USA. b.choi@uci.edu

Refers to the following texts of the Journal: 2019;45(3):239-247 1993;19(1):21-28

Key terms: JEM; job exposure matrix; letter; self report; self-reported data

This article in PubMed: www.ncbi.nlm.nih.gov/pubmed/30976814 


\section{Determining an optimal minimum number of subjects in each occupation for a job exposure matrix (JEM) using self-reported data: a missing test}

I read with great interest the paper by Hanvold et al (1) about the construction and evaluation of a gender-specific job exposure matrix (JEM) of mechanical and psychosocial work exposures using a Norwegian national survey data. I have found one significant methodological issue in the paper. In addition, I would like to discuss an important knowledge gap in the literature that the paper by Hanvold et al exposes.

The authors said that "...Earlier studies recommend 10 subjects in each group to achieve a reliable estimation of exposures, however, we used a minimum of 19 in each occupational group to increase the reliability of the estimates." The earlier study referred to here is that of Le Moual et al (2). However, like other investigators (3), the authors have misunderstood this paper. Le Moual et al did not make any recommendation for a minimum number of subjects in each occupation for creating a JEM. In fact, Le Moural et al (2) constructed their JEMs with 2, not 10 subjects, as the minimum number of subjects in each occupation (see a note in table 1: one exclusion criterion for their JEM was "occupations $<2$ subjects"). Hanvold et al's misunderstanding of the paper by Le Moural et al undermines the validity of their decision: 19 subjects as the minimum number of subjects in each occupation for their JEM.

The paper by Hanvold et al points to the fact that there is no strong empirical basis in the literature for an optimal minimum number of subjects in each occupation for creating a JEM using self-reported data. Several investigators, without appropriate tests, have used different minimum numbers of subjects in each occupation for their JEM of psychosocial exposures: 3 subjects (4), 4 subjects (5), and 10 subjects (3). It is very important to find an optimal minimum number of subjects in each occupation when creating a JEM that will provide a good balance between precision and specificity of exposure estimates. Requiring more subjects as the minimum number of subjects in each occupation for a JEM will result in more precise exposure estimates; however, it will be only for the occupations with at least the minimum number of subjects. In contrast, the occupations with insufficient numbers of subjects can be excluded from a JEM unless they are merged with related occupations into a broader occupation group. However, in the latter case, their exposure estimates will be diluted (less specific) due to the influence of the related occupations.
Requiring fewer subjects in each occupation will result in more occupation-specific exposure estimates in a JEM, while the exposure estimates will lose precision to some extent.

The authors reported that about half of the total 330 detailed occupations (4-digit level in STYRK 1998) available in their Norwegian data had $\leq 18$ subjects, which means that their exposure estimates had to be estimated after the merge with related occupations. This indirect (merged) exposure estimation approach was more frequently applied to female occupations. The authors could have created and tested alternative JEM with $<19$ subjects as the minimum number of subjects in each occupation. The results with the alternative JEM may substantially differ from those in Hanvold et al's paper (eg, gender differential performance of the JEM for mechanical and psychosocial exposures).

Rather than creating a JEM with an unsubstantiated minimum number of subjects, several JEM with varying minimum (particularly $2-10$ ) numbers of subjects need to be created and tested against individual self-reports in terms of exposure classification and associations with health outcomes. Based on the test, investigators would be able to select one of them as the best JEM with an optimal minimum number of subjects in each occupation.

\section{References}

1. Hanvold TN, Sterud T, Kristensen P, Mehlum IS. Mechanical and psychosocial work exposures: the construction and evaluation of a gender-specific job exposure matrix (JEM). Scand J Work Environ Health.2019;45(3):239-247. https:// doi.org/10.5271/sjweh.3774.

2. Le Moual N, Bakke P, Orlowski E, Heederik D, Kromhout $\mathrm{H}$, Kennedy SM et al. Performance of population specific job exposure matrices (JEMs): european collaborative analyses on occupational risk factors for chronic obstructive pulmonary disease with job exposure matrices (ECOJEM). Occup Environ Med. 2000 Feb;57(2):126-32. https://doi. org/10.1136/oem.57.2.126.

3. Solovieva S, Pensola T, Kausto J, Shiri R, Heliövaara M, Burdorf A et al. Evaluation of the validity of job exposure matrix for psychosocial factors at work. PLoS One 2014 Sep;9(9):e108987. https://doi.org/10.1371/journal. pone. 0108987 . 
4. Schwartz JE, Pieper CF, Karasek RA. A procedure for linking psychosocial job characteristics data to health surveys. Am J Public Health 1988 Aug;78(8):904-9. https:// doi.org/10.2105/AJPH.78.8.904.

5. Johnson JV, Stewart WF. Measuring work organization exposure over the life course with a job-exposure matrix. Scand J Work Environ Health. 1993 Feb;19(1):21-8. https:// doi.org/10.5271/sjweh. 1508 .
BongKyoo Choi, ScD, MPH, ${ }^{1,2}$

1 Department of Medicine, University of California Irvine, Irvine, CA, USA

2 Center for Work and Health Research, Irvine, CA, USA

Correspondence to: BongKyoo Choi, Department of Medicine and Program in Public Health, University of California Irvine, 100 Theory, Suite 100, Irvine, CA 92617, USA. [E-mail: b.choi@uci.edu] 